\title{
Risk factors and outcomes for prolonged versus brief fever: a prospective cohort study
}

\author{
Philippe Seguin ${ }^{1,2,3^{*}}$, Antoine Roquilly ${ }^{4}$, Olivier Mimoz ${ }^{5,6}$, Pascale Le Maguet ${ }^{1}$, Karim Asehnoune ${ }^{4}$, \\ Sébastien Biederman ${ }^{1}$, Elsa Carise $e^{5}$ and Yannick Malledant ${ }^{1,2,3}$, for the AtlanRea Group
}

\begin{abstract}
Introduction: Prolonged fever occurs with infectious and noninfectious diseases but is poorly studied in intensive care units. The aims of this prospective multicenter noninterventional study were to determine the incidence and etiologies of prolonged fever in critically ill patients and to compare outcomes for prolonged fever and shortlasting fever.
\end{abstract}

Methods: The study involved two periods of 2 months each, with 507 patients hospitalized $\geq 24$ hours. Fever was defined by at least one episode of temperature $\geq 38.3^{\circ} \mathrm{C}$, and prolonged fever, as lasting $>5$ days. Backward stepwise logistic regression was performed to identify the independent factors associated with prolonged fever versus short-lasting fever.

Results: Prolonged or short-lasting fever occurred in 87 (17\%) and 278 (55\%) patients, respectively. Infectious and noninfectious causes were found in 54 (62\%) and 27 (31\%) of 87 patients, respectively; in six patients (7\%), prolonged fever remained unexplained. The two most common sites of infection were ventilator-associated pneumonia $(n=25)$ and intraabdominal infection $(n=13)$. Noninfectious fever $(n=27)$ was neurogenic in 19 (70\%) patients and mainly associated with cerebral injury (84\%). Independent risk factors for prolonged fever were cerebral injury at admission $(\mathrm{OR}=5.03 ; 95 \% \mathrm{Cl}, 2.51$ to 10.06), severe sepsis ( $\mathrm{OR}=2.79 ; 95 \% \mathrm{Cl}, 1.35$ to 5.79$)$, number of infections $(\mathrm{OR}=2.35 ; 95 \% \mathrm{Cl}, 1.43$ to 3.86$)$, and mechanical-ventilation duration $(\mathrm{OR}=1.05 ; 95 \% \mathrm{Cl}, 1.01$ to 1.09). Older patients were less likely to develop prolonged fever. ICU mortality did not differ between the two groups.

Conclusions: Prolonged fever was common, mainly due to severe infections, particularly ventilator-associated pneumonia, and mixed infectious causes were frequent, warranting systematic and careful search for multiple causes. Neurogenic fever was also especially frequent.

\section{Introduction}

Fever is a frequent symptom in the intensive care unit (ICU), with rates ranging from $28 \%$ to $70 \%$; its frequency depends of the types of patients evaluated, the threshold of definition of fever, and the duration of evaluation [1-4]. In a large, recent retrospective study involving more than 20,000 types of intensive care patients in the same hospital, fever $\left(\geq 38.3^{\circ} \mathrm{C}\right)$ and high fever $\left(>39.5^{\circ} \mathrm{C}\right)$ were reported in $44 \%$ and $8 \%$, respectively [2].

If evaluation of new-onset fever in intensive care adult patients is well standardized [5], the problem caused by

\footnotetext{
* Correspondence: philippe.seguin@chu-rennes.fr

'Département d'Anesthésie Réanimation, CHU Rennes, 2 rue Henri Le Guilloux, Rennes F-35033, France

Full list of author information is available at the end of the article
}

prolonged fever ( $>5$ days) has not been well studied, although it has been recognized to occur in $8 \%$ to $18 \%$ of patients and is related mainly to infectious etiologies [1-3]. These findings urge us to define better the spectrum of prolonged fever in a wide population of critically ill patients. Indeed, we hypothesized that prolonged fever may have a high percentage of noninfectious causes and/ or particular etiologies that could modify the care of critically ill patients.

Accordingly, the objectives of this study were to determine the incidence and etiologies of prolonged fever, to evaluate morbidity and mortality of fever, and to determine its risk factors compared with short-lasting fever in patients in the ICU.

\section{Biomed Central}




\section{Materials and methods}

This prospective observational study was conducted in three surgical ICUs in university hospitals in France (Nantes, Poitiers, and Rennes), and included two periods of 2 months each (May 1, 2010, to June 30, 2010, and September 1, 2010, to October 31, 2010) to avoid possible temporal etiology variations. During the two periods of study, a total of 596 patients were admitted in the ICUs, and 507 patients hospitalized $\geq 24$ hours in the ICUs were analyzed (Figure 1). The local ethics committee waived informed consent because this was a noninterventional study (Comité d'éthique du CHU de Rennes, France, $\left.n^{\circ} 10.03\right)$.

At least every 6 hours (or more frequently if the clinical conditions required), nurses measured the patients' core temperatures at the axilla by using a digital thermometer according to the recommendations of the manufacturer (Thermofina; Z.A.C. Chamlys, Dammarie-Les-Lys, France). The temperature recorded was that provided when the acoustic signal was heard and by adding $0.5^{\circ} \mathrm{C}$. When a pulmonary artery catheter was in place, the temperature recorded was obtained through this device.

At admission, the following data were recorded: age, gender, McCabe score, type of admission (medical, scheduled or nonscheduled surgery, and trauma), and presence of a cerebral injury, whatever the origin at admission. Severity was assessed by the severity acute physiology score II (SAPS II) and sequential organ failure assessment (SOFA). The presence of an infection, bacteremia, and the infected sites were also recorded.

During the ICU hospitalization, the number of infected patients, the mean number of infections per patient, the infected sites, the occurrence of bacteremia, severe sepsis or septic shock, antibiotic use and its duration, the duration of mechanical ventilation, and development of acute respiratory distress syndrome (ARDS) or acute renal failure were noted. Maximum leukocyte counts and C-reactive protein levels measured during the ICU stay were recorded. Acetaminophen (grams per day) or extracorporeal devices used (continuous renal replacement therapy or extracorporeal membrane oxygenation), known to interfere with the magnitude of the temperature, were reported. The ICU and hospital lengths of stay and ICU mortality were also recorded. The proportion of microorganisms recovered at admission and during the ICU stay were recorded and divided into those cultured from normally sterile sites (blood, mediastinum, intraabdominal, and others) and those cultured from potentially contaminated sites (urine, endotracheal tube aspirate, and others).

The search for the etiology of prolonged fever was left to the discretion of the physicians. Nevertheless, careful consideration was deemed necessary for viral infection, venous thrombosis, and evaluation of the possibility of medication-induced fever. Final diagnosis of infection was made,

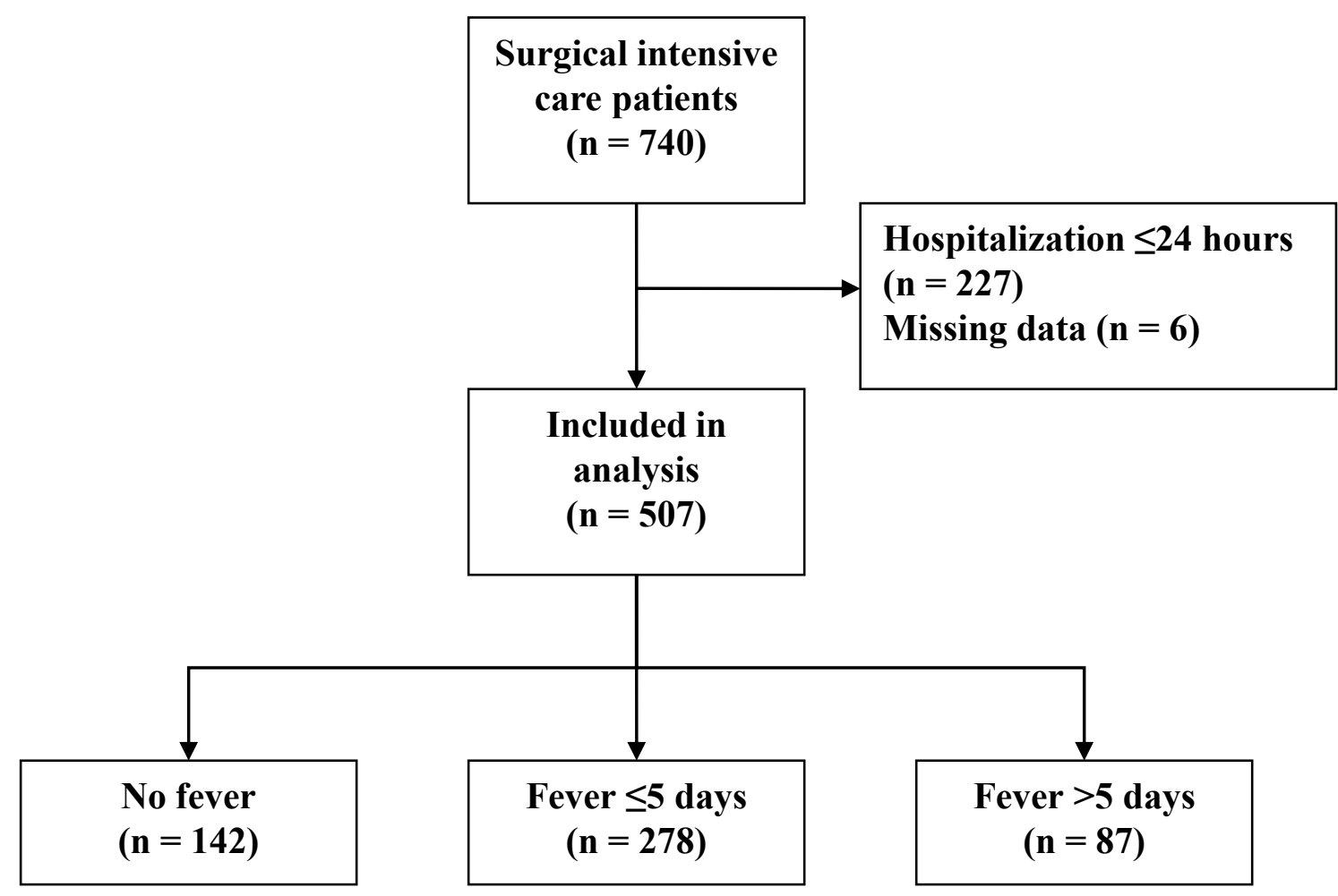

Figure 1 Trial profile. 
according to the definitions proposed by the International Sepsis Forum Consensus Conference [6] at the end of the ICU hospitalization by an experienced and independent intensivist at each center.

\section{Definitions}

Fever was defined as at least one episode of temperature $\geq 38.3^{\circ} \mathrm{C}$, and prolonged fever as that lasting at least 5 days, as previously reported [1-3,5]. Surgical patients were those who had undergone surgery in the 4 weeks preceding admission (elective surgery was a surgery scheduled $>24$ hours in advance, and emergency surgery was that scheduled within 24 hours of operation). Trauma admissions were defined as ICU admissions directly related to, or occurring as a complication of, a traumatic event in the 30 days preceding admission. Neurogenic fever refers to unexplained fever in patients who had a cerebral injury, whatever the cause, and was retained after thorough investigations for infectious and noninfectious causes. Unexplained fever in other types of patients referred to patients without cerebral injury and retained after thorough investigations for infectious and non-infectious causes. Sepsis, severe sepsis, and septic shock were defined accordingly to the Bone criteria [7], and ARDS, as persistent and bilateral opacities on chest radiographs associated with a $\mathrm{PaO}_{2} / \mathrm{FiO}_{2}$ ratio < 200 without cardiac failure or left atrial hypertension [8]. Acute renal failure was defined as a serum creatinine concentration $>4 \mathrm{mg} / \mathrm{dl}(350 \mu \mathrm{M})$, or an acute increase in serum creatinine concentration $(3 \times$ baseline value), or a urine output $<0.3 \mathrm{ml} / \mathrm{kg}$ during 12 hours or anuria during 12 hours [9].

\section{Statistical analysis}

All statistical analyses were performed by using SAS 9.1 Statistical Software (SAS Institute, Cary, NC, USA). Values are expressed as means (standard deviation) or medians (interquartile range) and as numbers (\%) as required. Patients were separated into two independent groups: prolonged fever and short-lasting fever. First, categoric variables were compared by using the $\chi^{2}$ or Fisher Exact test. Continuous variables were compared by using the Student $t$ test. For building the model in multivariate analysis, we selected variables with an external clinical judgment among those with a $P \leq 0.20$ in univariate analysis. Backward stepwise logistic regression was performed to identify the independent factors associated with prolonged fever. The calibration of the models was tested with a Hosmel-Lemeshow test. Bootstrap procedure with repeated sampling was performed to validate the model stability. Odds ratios (ORs) and 95\% confidence intervals (95\% CIs) were calculated. $P<$ 0.05 was considered statistically significant.

\section{Results}

Prolonged fever was observed in 87 (17\%) of 507 patients. Body temperature was measured in the pulmonary artery catheter in $86(17 \%)$ of 507 of our patients, this catheter being inserted for a mean duration of $5.4 \pm 1.5$ days. Table 1 lists the baseline characteristics of the patients.

Ninety-seven etiologies of prolonged fever were found in 87 patients and detailed in Table 2. Infectious and noninfectious causes were found in $54(62 \%)$ and 27 (31\%) of 87 patients, respectively, and prolonged fever remained unexplained in six (7\%) patients. In 14 (16\%) patients, prolonged fever was related to several causes; the main association was infective in 10 of 14 patients, and in four cases, the cause could not be distinguished between an infectious or a noninfectious cause. More than one cause of prolonged fever was significantly less frequent in patients who had shorter durations of fever (five of 278 versus 14 of $87 ; P<0.001$ ).

The two most common types of infection were ventilator-associated pneumonia (VAP) and intraabdominal infection. VAP was associated with one $(n=9)$ or two $(n=1)$ other causes for prolonged fever, mainly another infection (seven of 10). Intraabdominal infection was the only cause of prolonged fever in 10 of 13 patients. Catheter-related infection was the third most common infectious cause of prolonged fever, but in four of six patients, it was associated with other possible causes (intraabdominal infection, $n=2$; VAP, $n=2$; and venous thrombosis, $n=1$ ). The proportion of microorganisms recovered at admission and during ICU stay between those cultured from normally sterile sites and those cultured from potentially contaminated sites is displayed in Figure 2.

In noninfectious causes of fever, neurogenic fevers were predominant, observed in 19 of 27 patients and mainly (16 of 19) in those who had cerebral injury at admission (Table 2). All but one case of neurogenic fever was the only cause recognized for prolonged fever. A thrombosis was found in four patients, but considered the only cause of prolonged fever in only one patient (arterial thrombosis).

Univariate analysis is presented in Tables 1 and 3. In patients who had cerebral injury at admission, the incidence of neurogenic fever did not differ between trauma and nontrauma patients, whereas infections were more frequently observed in trauma patients (eight of 30 versus eight of $15 ; P=0.152$; and 20 of 30 versus five of $15, P=0.071$, respectively). Finally, ICU and hospital lengths of stay were increased, whereas ICU mortality rates did not differ between the two groups (Table 4).

Age, SOFA, MacCabe, cerebral injury at admission, severe sepsis, septic shock, ARDS, thrombosis, number of 


\begin{tabular}{|c|c|c|c|c|}
\hline & \multirow[b]{2}{*}{$\begin{array}{l}\text { No fever } \\
(n=142)\end{array}$} & \multicolumn{3}{|l|}{ Fever } \\
\hline & & $\begin{array}{l}\leq 5 \text { days } \\
(n=278)\end{array}$ & $\begin{array}{l}>5 \text { days } \\
(n=87)\end{array}$ & $P$ \\
\hline Age, years & $58 \pm 18$ & $58 \pm 18$ & $52 \pm 17$ & 0.005 \\
\hline Sex, male & $92(65)$ & $187(67)$ & $63(72)$ & 0.37 \\
\hline McCabe score & & & & 0.05 \\
\hline A & $72(51)$ & $151(54)$ & $63(72)$ & \\
\hline B & $51(36)$ & $97(35)$ & $17(20)$ & \\
\hline C & $19(13)$ & $29(10)$ & $7(8)$ & \\
\hline Type of admission & & & & 0.005 \\
\hline Medical & $34(24)$ & $64(23)$ & $15(17)$ & \\
\hline Scheduled surgery & $44(31)$ & $73(26)$ & $10(11)$ & \\
\hline Unscheduled surgery & $39(27)$ & $61(22)$ & $24(28)$ & \\
\hline Trauma & $25(18)$ & $80(29)$ & $38(44)$ & \\
\hline Cerebral injury at admission & $13(9)$ & $69(25)$ & $45(52)$ & $<0.001$ \\
\hline SAPS $\|$ & $34 \pm 19$ & $42 \pm 19$ & $45 \pm 16$ & 0.16 \\
\hline SOFA at admission & $4 \pm 4$ & $6 \pm 4$ & $8 \pm 4$ & $<0.001$ \\
\hline \multicolumn{5}{|l|}{ At admission } \\
\hline Infection & $32(23)$ & $72(25)$ & $21(24)$ & 0.74 \\
\hline Bacteremia & $6(4)$ & $16(6)$ & $5(6)$ & 1.00 \\
\hline Site infected & & & & 0.98 \\
\hline Lungs & $9(6)$ & $16(6)$ & $6(7)$ & \\
\hline Intraabdominal & $18(13)$ & $30(11)$ & $10(11)$ & \\
\hline Urine & $4(3)$ & $2(1)$ & $0(0)$ & \\
\hline Catheter & $0(0)$ & $1(1)$ & $0(0)$ & \\
\hline Others & $7(5)$ & $23(8)$ & $5(6)$ & \\
\hline
\end{tabular}

Comparisons are given between a fever of $\leq 5$ and $>5$ days. Quantitative and qualitative values are expressed as mean (SD) and $n$ (\%), respectively. SAPS II, Simplified Acute Physiologic Score II; SOFA, Sequential Organ Failure Assessment.

infections during ICU hospitalization, and duration of mechanical ventilation were variables entered for the multivariate analysis. Independent risk factors for prolonged fever were cerebral injury at admission $(\mathrm{OR}=5.03$; 95\% CI, 2.51 to10.06), severe sepsis ( $\mathrm{OR}=2.79 ; 95 \% \mathrm{CI}, 1.35$ to 5.79 ), number of infections ( $\mathrm{OR}=2.35 ; 95 \% \mathrm{CI}, 1.43$ to $3.86)$, and mechanical ventilation duration $(\mathrm{OR}=1.05$; $95 \%$ CI, 1.01 to 1.09 ). The model predicted well the risk for prolonged fever $(\mathrm{C}$-index $=0.89)$. Age was protective $(\mathrm{OR}=0.97 ; 95 \% \mathrm{CI}, 0.96$ to 0.99$)$, with older patients being less susceptible to developing prolonged fever.

\section{Discussion}

In this prospective study involving a large population of critically ill patients, $17 \%$ of patients experienced prolonged fever. Infections were the leading cause, and VAP, the main infection; the number of infections, the presence of severe sepsis, and mechanical ventilation duration were independent risk factors. Noninfectious causes were mainly neurogenic, and cerebral injury at admission was an independent risk factor. Finally, older patients were less susceptible to prolonged fever. Prolonged fever did not affect the mortality when compared with shorter-lasting fever.
Few studies have evaluated the incidence of prolonged fever in critically ill patients, and none has specifically focused on it. Notably, none described the precise etiologies and evaluated the clinical relevance. In 100 consecutive patients, prolonged fever was reported in 16\%; an infective cause was recognized in all patients [1]. More recently, in a prospective study in 493 patients, prolonged fever was found in $8 \%$ and was also reported to be due to an infectious cause in 74\% [3]. Finally, in a retrospective study involving more than 20,000 patients, prolonged fever was found in 18\% [2]. The strength of our study lies in its multicenter and prospective design, performed during two time periods to avoid possible temporal etiology variations, and precise description of causes. Prolonged fever was present in $17 \%$. Infection was the main cause, but less frequently than previously reported $[1,3]$. The first interesting and surprising finding is that the most common infective site involved was related to VAP, followed by intraabdominal sites. Nevertheless, one report indicated that times to resolution of temperature, improvement of the $\mathrm{PaO}_{2} / \mathrm{FiO}_{2}$ ratio, and improvement in leukocyte counts after antimicrobial therapy in patients with VAP were low; the mean time to resolution of these clinical parameters was 6 days 
Table 2 Detailed etiologies for prolonged fever

\begin{tabular}{|c|c|}
\hline Causes & \\
\hline \multicolumn{2}{|l|}{ Infectious } \\
\hline Ventilator-associated pneumonia & $24^{a}$ \\
\hline Intraabdominal infection ${ }^{\mathrm{b}}$ & 13 \\
\hline Catheter-related infection ${ }^{c}$ & 6 \\
\hline Postoperative mediastinitis & 5 \\
\hline Urinary & 4 \\
\hline Sinusitis & 3 \\
\hline Wounds & 3 \\
\hline Others $^{d}$ & 12 \\
\hline \multicolumn{2}{|l|}{ Noninfectious } \\
\hline Neurologic & 19 \\
\hline Thrombosis & 4 \\
\hline Medications & 1 \\
\hline Others $^{\mathrm{e}}$ & 3 \\
\hline Unknown & 6 \\
\hline \multicolumn{2}{|l|}{ Mixed causes } \\
\hline Infectious & 10 \\
\hline 2 & 9 \\
\hline 3 & 1 \\
\hline Infectious and noninfectious & 4 \\
\hline
\end{tabular}

Values are expressed as etiologies per patient. ${ }^{a}$ One patient experienced two episodes of ventilator-associated pneumonia; ventilator-associated pneumonia,

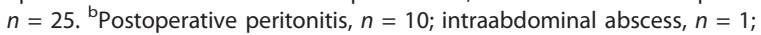
pancreatitis, $n=1$; and colitis, $n=1$. 'Central venous catheter, $n=5$, and arterial catheter, $n=1$. dProsthetic infection, $n=2$; cellulitis, $n=2$; viral, $n=2$; aspiration, $n=2$; empyema, $n=1$; Lyell syndrome, $n=1$; endocarditis, $n=1$;

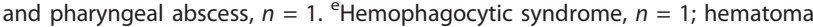
resorption, $n=1$; and arthritis, $n=1$.

[10]. More recently, another study reported that in patients who had VAP with and without ARDS, fever $(\geq$ $38^{\circ} \mathrm{C}$ ) was still present in $85 \%$ and $25 \%$ after 72 hours, respectively, despite appropriate antimicrobial therapy [11].

In our study, the duration of mechanical ventilation was an independent risk factor for prolonged fever and must be interpreted in light of the high incidence of VAP, which in turn, prolonged the need for mechanical ventilation.

The second finding that merits emphasis is the multiple causes of infective prolonged fever. Accordingly, our finding argues for systematically searching for another cause of prolonged fever, notably concomitant infection. Finally, according to the high infection rate observed in patients with prolonged fever, it not surprising that in multivariate analysis, the number of infections was an independent risk factor.

Severe sepsis was an independent risk factor for prolonged fever. Proinflammatory cytokines (endogenous pyrogens) have a central role in the genesis of fever, and high and prolonged levels of cytokines are expressed in patients with severe sepsis $[12,13]$. The fact that severe sepsis favors prolonged fever more than septic shock,

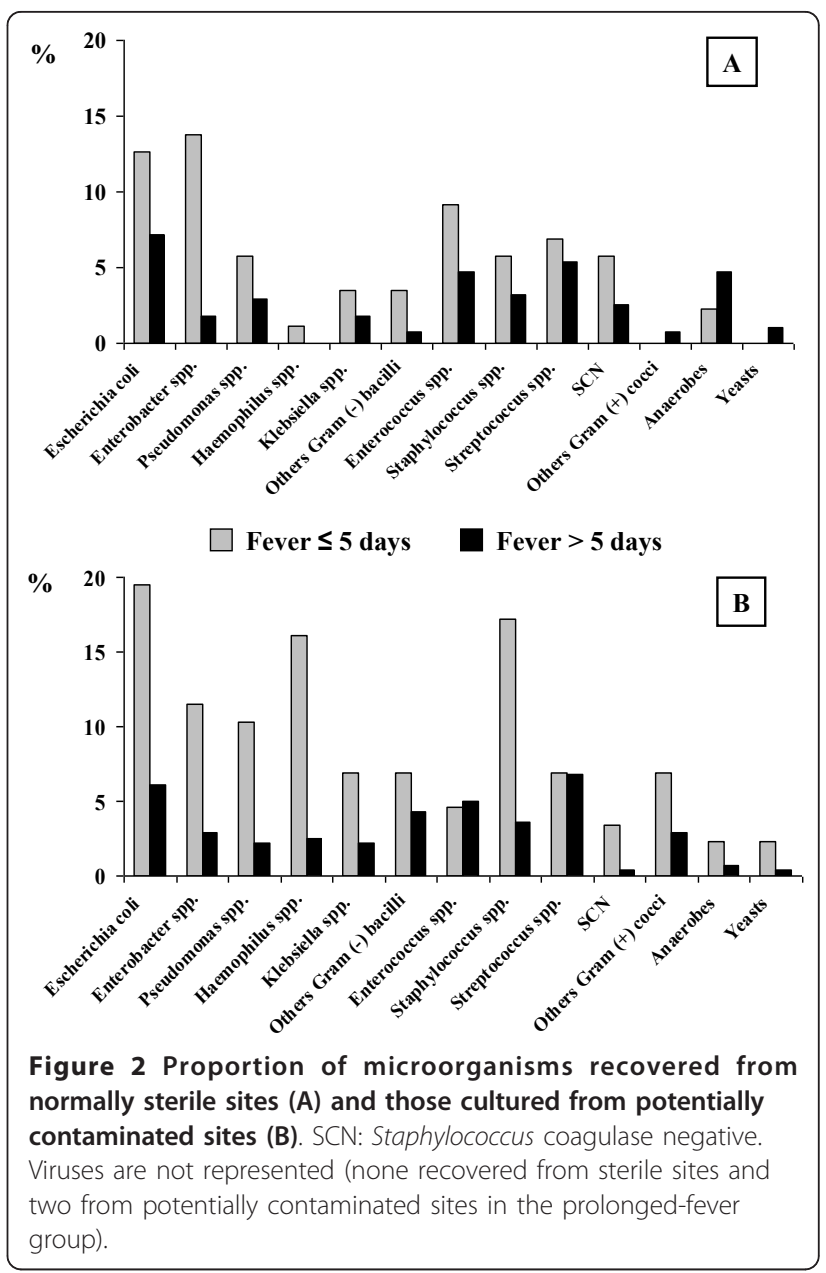

which produces the highest cytokines levels, is surprising. Nevertheless, in about $10 \%$ of the most severely ill sepsis patients, the febrile response was blunted despite an augmented cytokine response, when compared with that in febrile patients [14].

In our study, involving a heterogeneous population of neurologic patients in the ICU, neurogenic fever was the second and the leading noninfectious cause for prolonged fever. Neurogenic fever was observed in $84 \%$ of patients who had cerebral injury, and this explains why cerebral injury at admission was found to be an independent risk factor. Fever in neurologic ICU patients is common, and its incidence ranged from $22 \%$ to $47 \%[15,16]$. Specifically, neurogenic fever was reported in $28 \%$ and $29 \%$, and preferentially in patients with subarachnoid hemorrhage $[15,17]$. Our results are in accordance with such findings and emphasize the value of neurologic injury as a cause of prolonged fever, but we did not find a difference between traumatic and nontraumatic brain injury.

Among risk factors for prolonged fever, older patients were less susceptible to developing prolonged fever. Thermoregulation mechanisms are well preserved in the 
Table 3 Clinical and biologic data during ICU hospitalization

\begin{tabular}{|c|c|c|c|c|}
\hline & & Fever & & \\
\hline & $\begin{array}{l}\text { No fever } \\
(n=142)\end{array}$ & $\begin{array}{l}\leq 5 \text { days } \\
(n=278)\end{array}$ & $\begin{array}{l}>5 \text { days } \\
(n=87)\end{array}$ & $P$ \\
\hline No. infected patients & $35(25)$ & $133(49)$ & $59(68)$ & 0.002 \\
\hline No. infections/patient & $0.3 \pm 0.6$ & $0.6 \pm 0.7$ & $1.6 \pm 1.0$ & $<0.001$ \\
\hline Site infected & & & & 0.84 \\
\hline Lungs & $8(6)$ & $99(36)$ & $53(61)$ & \\
\hline Intraabdominal & $9(6)$ & $21(8)$ & $5(6)$ & \\
\hline Urine & $0(0)$ & $26(9)$ & $15(17)$ & \\
\hline Catheter & $0(0)$ & $14(5)$ & $11(13)$ & \\
\hline Others & $18(13)$ & $43(15)$ & $16(18)$ & \\
\hline Bacteremia during ICU stay & $2(1)$ & $32(12)$ & $31(36)$ & 0.004 \\
\hline Severe sepsis & $21(15)$ & $62(22)$ & $49(56)$ & $<0.001$ \\
\hline Septic shock & $15(11)$ & $54(19)$ & $27(31)$ & 0.03 \\
\hline Antibiotic use & $31(22)$ & $119(43)$ & $75(86)$ & $<0.001$ \\
\hline Antibiotic duration, days & $2 \pm 4$ & $4 \pm 6$ & $13 \pm 14$ & $<0.001$ \\
\hline Mechanical ventilation duration, days & $2 \pm 3$ & $7 \pm 9$ & $21 \pm 19$ & $<0.001$ \\
\hline ARDS & $6(4)$ & $19(7)$ & $20(23)$ & $<0.001$ \\
\hline Acute renal failure & $29(20)$ & $75(27)$ & $23(26)$ & 0.9 \\
\hline Acetaminophen use, g/day & $1.0 \pm 1.4$ & $0.7 \pm 0.2$ & $1.0 \pm 1.3$ & 0.02 \\
\hline Extracorporeal devices use & $8(6)$ & $39(14)$ & $15(17)$ & 0.57 \\
\hline Venous thrombosis & $0(0)$ & $13(5)$ & $9(10)$ & 0.052 \\
\hline Maximum leukocyte count, Giga/L & $15.0 \pm 7.3$ & $18.8 \pm 13.2$ & $20.3 \pm 11.7$ & 0.38 \\
\hline Maximum CRP level, mg/L & $121 \pm 99$ & $155 \pm 114$ & $158 \pm 103$ & 0.9 \\
\hline
\end{tabular}

Comparisons are given between a fever of $\leq 5$ and $>5$ days. Quantitative and qualitative values are expressed as mean (SD) and $n$ (\%), respectively. ICU, intensive care unit; ARDS, acute respiratory distress syndrome; CRP, C-reactive protein.

elderly [18]. Nevertheless, basal temperatures are lower in older people and in face of an infectious/inflammatory process, both experimental and human data argue for a lower febrile response in these patients, which may explain our result [3,19-21].

Interestingly, mortality did not differ between patients who had prolonged fever and those who had short-lasting fever. Our results do not agree with those in two studies that found a higher mortality rate in patients who had prolonged fever [1,3]. Nevertheless, the population we studied differed because we had a higher proportion of patients with cerebral injury or trauma or both. Fever has a detrimental effect on outcomes in patients with cerebral injury. Nevertheless, prolonged fever did not seem to

Table 4 Lengths of stay and ICU mortality

\begin{tabular}{cllll}
\hline & & Fever & & \\
\cline { 4 - 5 } & $\begin{array}{c}\text { No fever } \\
(\boldsymbol{n}=\mathbf{1 4 2})\end{array}$ & $\begin{array}{l}\mathbf{\leq} \mathbf{5} \text { days } \\
(\boldsymbol{n}=\mathbf{2 7 8})\end{array}$ & $\begin{array}{l}>\mathbf{5} \text { days } \\
(\boldsymbol{n}=\mathbf{8 7})\end{array}$ & $\boldsymbol{P}$ \\
\hline Lengths of stay, days & & & & \\
ICU & $5 \pm 4$ & $10 \pm 9$ & $27 \pm 24$ & $<0.001$ \\
Hospital & $25 \pm 30$ & $27 \pm 27$ & $53 \pm 42$ & $<0.001$ \\
ICU mortality & $18(13)$ & $53(19)$ & $13(15)$ & 0.38 \\
\hline
\end{tabular}

Comparisons are given between a fever of $\leq 5$ and $>5$ days. Quantitative and qualitative values are expressed as mean (SD) and $n(\%)$, respectively. ICU, intensive care unit. worsen the prognosis when compared with a shorter duration of fever. Moreover, VAP represented the main infective cause of prolonged fever in our patients, and some studies have shown no evidence of an attributable mortality to VAP in trauma patients [22,23].

Our study has some limitations. The definition of prolonged fever could be disputed. The end point of 5 days may appear too rigid, and it could be more relevant to consider prolonged fever as one that persists after wellconducted antimicrobial therapy in cases of infection or after a negative exhaustive screening search for infection. Nevertheless, three epidemiologic studies previously retained the threshold of 5 days for prolonged fever in the ICU. The definitions and method we used to determine infectious and noninfectious causes of fever may lead to over- or underdiagnoses, particularly in some circumstances in which the diagnosis is difficult and/or nonspecific definitions exist (in VAP, in particular). Conversely, all the data were reviewed at the end of each hospitalization, and according to the definitions proposed, by an experienced and independent intensivist at each center, and we believe that such an approach allows reducing the errors that could be inherent in the design of our study. The method of temperature measurements we used could be criticized; the optimal site of core temperature is provided by the pulmonary artery catheter, 
although this method is limited to patients requiring such a device [5]. In critically ill patients, the temperaturemeasurement site is controversial, and in fact, when compared with other sites in adult patients in the ICU, the axillary method remains accurate enough to be used in clinical practice [24-26]. Moreover, it has been proposed that axillary measurement with a digital thermometer has several advantages: it is easy to use, comfortable, secure, inexpensive, and durable [27-29].

Finally, this study was performed in surgical intensive care units, and our results could not be extrapolated to medical patients, who are underrepresented.

\section{Conclusions}

Prolonged fever is common in critically ill patients and is mainly due to severe infections, particularly VAP. Mixed causes were frequently recognized, notably infective, and such an association warrants systematic and careful search for causes. Neurogenic fever was a frequent cause of prolonged fever in patients with cerebral injury and often observed as the only cause. Mortality did not differ from shorter lasting fever.

\section{Key messages}

- Prolonged fever is common in critically ill patients. - Ventilator-associated pneumonia is the leading cause of prolonged fever.

- More than one infectious or noninfectious cause must be carefully researched.

- In patients with cerebral injury, neurogenic fever was a frequent cause of prolonged fever and often observed as the only cause.

\begin{abstract}
Abbreviations
ARDS: Acute respiratory distress syndrome; ICU: intensive care unit; SOFA: Sequential Organ-failure Assessment; SAPS II: Severity Acute Physiology Score II; VAP: ventilator-associated pneumonia.

\section{Author details \\ 'Département d'Anesthésie Réanimation, CHU Rennes, 2 rue Henri Le Guilloux, Rennes F-35033, France. ${ }^{2}$ Inserm U991, 2 avenue du Professeur Léon Bernard, Rennes F-35043, France. ' Université Rennes 1. F-35043 Rennes, France. ${ }^{4}$ Département d'Anesthésie Réanimation, CHU Nantes, Place Alexis Ricordeau, F-44093 Nantes, France. ${ }^{5}$ Département d'Anesthésie Réanimation, CHU Poitiers, 2 rue de la Milétrie, Poitiers F-86021, France. ${ }^{6}$ Inserm Eri 23, 40 avenue du recteur Pineau, Poitiers F-86022, France.}

\section{Authors' contributions}

PS made an important contribution to the conception and interpretation of the data and wrote the final manuscript version. AR, OM, and KA made an important contribution to acquisition, data analysis, and to the final manuscript version. SB and EC made an important contribution to acquisition and data analysis. PLM made a substantial contribution in the statistical design and analysis and acquisition of data. YM made an important contribution to the final manuscript version. All authors read and approved the manuscript for publication.

\section{Competing interests}

The authors declare that they have no competing interests.
Received: 2 March 2012 Revised: 23 July 2012

Accepted: 13 August 2012 Published: 13 August 2012

\section{References}

1. Circiumaru B, Baldock $G$, Cohen J: A prospective study of fever in the intensive care unit. Intensive Care Med 1999, 25:668-673.

2. Laupland KB, Shahpori R, Kirkpatrick AW, Ross T, Gregson DB, Stelfox HT: Occurrence and outcome of fever in critically ill adults. Crit Care Med 2008, 36:1531-1535.

3. Peres Bota D, Lopes Ferreira F, Melot C, Vincent JL: Body temperature alterations in the critically ill. Intensive Care Med 2004, 30:811-816.

4. Thong WY, Strickler AG, Li S, Stewart EE, Stewart EE, Collier CL, Vaughn WK, Nussmeier NA: Hyperthermia in the forty-eight hours after cardiopulmonary bypass. Anesth Analg 2002, 95:1489-1495.

5. O'Grady NP, Barie PS, Bartlett JG, Bleck T, Carroll K, Kalil AC, Linden P, Maki DG, Nierman D, Pasculle W, Masur H, the American College of Critical Care Medicine, Infectious Diseases, Society of America: Guidelines for evaluation of new fever in critically ill adult patients: 2008 update from the American College of Critical Care Medicine and the Infectious Diseases Society of America. Crit Care Med 2008, 36:1330-1349.

6. Calandra T, Cohen J: The International Sepsis Forum Consensus Conference on definitions of infection in the intensive care unit. Crit Care Med 2005, 33:1538-1548.

7. Bone RC, Balk RA, Cerra FB, Dellinger RP, Fein AM, Knaus WA, Schein RM, Sibbald WJ: Definitions for sepsis and organ failure and guidelines for the use of innovative therapies in sepsis: The ACCP/SCCM Consensus Conference Committee, American College of Chest Physicians/Society of Critical Care Medicine. Chest 1992, 101:1644-1655.

8. Bernard GR, Artigas A, Brigham KL, Carlet J, Falke K, Hudson L, Lamy M, Legall JR, Morris A, Spragg R: The American-European Consensus Conference on ARDS: definitions, mechanisms, relevant outcomes, and clinical trial coordination. Am J Respir Crit Care Med 1994, 149:818-824.

9. Bellomo R, Ronco C, Kellum JA, Mehta RL, Palevsky P: Acute renal failure: definition, outcome measures, animal models, fluid therapy and information technology needs: the Second International Consensus Conference of the Acute Dialysis Quality Initiative (ADQI) Group. Crit Care 2004, 8:R204-R212.

10. Dennesen PJ, van der Ven AJ, Kessels AG, Ramsay G, Bonten MJ: Resolution of infectious parameters after antimicrobial therapy in patients with ventilator-associated pneumonia. Am J Respir Crit Care Med 2001, 163:1371-1375.

11. Vidaur L, Gualis B, Rodriguez A, Ramírez R, Sandiumenge A, Sirgo G, Diaz E, Rello J: Clinical resolution in patients with suspicion of ventilatorassociated pneumonia: a cohort study comparing patients with and without acute respiratory distress syndrome. Crit Care Med 2005, 33:1248-1253.

12. Gogos CA, Drosou E, Bassaris HP, Skoutelis A: Pro- versus antiinflammatory cytokine profile in patients with severe sepsis: a marker for prognosis and future therapeutic options. J Infect Dis 2000, 181:176-180.

13. Launey $Y$, Nesseler $N$, Malledant $Y$, Seguin P: Clinical review: fever in septic ICU patients: friend or foe? Crit Care 2011, 15:222.

14. Arons MM, Wheeler AP, Bernard GR, Christman BW, Russell JA, Schein R, Summer WR, Steinberg KP, Fulkerson W, Wright P, Dupont WD, Swindell BB: Effects of ibuprofen on the physiology and survival of hypothermic sepsis: Ibuprofen in Sepsis Study Group. Crit Care Med 1999, 27:699-707.

15. Commichau C, Scarmeas N, Mayer SA: Risk factors for fever in the neurologic intensive care unit. Neurology 2003, 60:837-841.

16. Kilpatrick MM, Lowry DW, Firlik AD, Yonas H, Marion DW: Hyperthermia in the neurosurgical intensive care unit. Neurosurgery 2000, 47:850-855.

17. Rabinstein AA, Sandhu K: Non-infectious fever in the neurological intensive care unit: incidence, causes and predictors. J Neurol Neurosurg Psychiatry 2007, 78:1278-1280

18. Sessler Dl: Thermoregulatory defense mechanisms. Crit Care Med 2009, 37(Suppl 7):203-210.

19. Barrientos RM, Watkins LR, Rudy JW, Maier SF: Characterization of the sickness response in young and aging rats following $E$. coli infection. Brain Behav Immun 2009, 23:450-454.

20. Miller D, Yoshikawa T, Castle SC, Norman D: Effect of age on fever response to recombinant tumor necrosis factor alpha in a murine model. J Gerontol 1991, 46:M176-M179. 
21. Roghmann MC, Warner J, Mackowiak PA: The relationship between age and fever magnitude. Am J Med Sci 2001, 322:68-70.

22. Leone $M$, Bourgoin A, Giuly E, Antonini F, Dubuc M, Viviand X, Albanèse J, Martin C: Influence on outcome of ventilator-associated pneumonia in multiple trauma patients with head trauma treated with selected digestive decontamination. Crit Care Med 2002, 30:1741-1746.

23. Melsen WG, Rovers MM, Bonten MJ: Ventilator-associated pneumonia and mortality: a systematic review of observational studies. Crit Care Med 2009, 37:2709-2718.

24. Lawson L, Bridges EJ, Ballou I, Eraker R, Greco S, Shively J, Sochulak V: Accuracy and precision of noninvasive temperature measurement in adult intensive care patients. Am J Crit Care 2007, 16:485-496.

25. Lefrant JY, Muller L, de La Coussaye JE, benbabaali M, Lebris C, Zeitoun N, Mari C, Saïssi G, Ripart J, Eledjam JJ: Temperature measurement in intensive care patients: comparison of urinary bladder, oesophageal, rectal, axillary, and inguinal methods versus pulmonary artery core method. Intensive Care Med 2003, 29:414-418.

26. Giuliano KK, Scott SS, Elliot S, Giuliano AJ: Temperature measurement in critically ill orally intubated adults: a comparison of pulmonary artery core, tympanic, and oral methods. Crit Care Med 1999, 27:2188-2193.

27. Rubia-Rubia J, Arias A, Sierra A, Aguirre-Jaime A: Measurement of body temperature in adult patients: comparative study of accuracy, reliability and validity of different devices. Int J Nurs Stud 2011, 48:872-880.

28. Myny D, De Waele J, Defloor T, Blot S, Colardyn F: Temporal scanner thermometry: a new method of core temperature estimation in ICU patients. Scott Med J 2005, 50:15-18.

29. Fadzil FM, Choon D, Arumugam K: A comparative study on the accuracy of noninvasive thermometers. Aust Fam Physician 2010, 39:237-239.

doi:10.1186/cc11465

Cite this article as: Seguin et al:: Risk factors and outcomes for prolonged versus brief fever: a prospective cohort study. Critical Care 2012 16:R150.

\section{Submit your next manuscript to BioMed Central and take full advantage of:}

- Convenient online submission

- Thorough peer review

- No space constraints or color figure charges

- Immediate publication on acceptance

- Inclusion in PubMed, CAS, Scopus and Google Scholar

- Research which is freely available for redistribution

Submit your manuscript at www.biomedcentral.com/submit 